\title{
A GAM no ES: invenções com crianças, familiares e trabalhadores
}

GAM in ES: inventions with children, family and workers

GAM en ES: inventos con niños, familiares y trabajadores

\author{
Luciana Vieira Caliman
}

Janaína Mariano César

Universidade Federal do Espírito Santo (UFES), Vitória, ES, Brasil

\section{Resumo}

Neste artigo, analisamos a experimentação da Estratégia GAM no Espírito Santo. O trabalho de pesquisa intervenção participativa com a GAM no percurso de cinco anos constituiu a montagem de três dispositivos. No campo da saúde mental infantojuvenil foram propostos um Grupo GAM com familiares de criançasque fazem uso de psicotrópicos e uma Oficina com crianças. O terceiro dispositivo envolveu a rede de saúde mental mais ampla, com a implementação da Estratégia GAM efetuada por trabalhadoras(es), tendo a Universidade como parceira a partir da criação de um dispositivo de Supervisão coletiva. Dimensionamos essa experiência como inauguradora de outros domínios de intervenção da GAM, compreendendo que tal abertura coloca em relevo o potencial desta estratégia e também o seu maior desafio: a capacidade de ser reinventada a cada experiência situada. Cada dispositivo criado tornou-se inseparável na construção da participaçãoque faz operar coletivos mais cogestivos e autônomos.

Palavras-chave: Gestão Autônoma da Medicação; Saúde Mental; Saúde Mental Infantojuvenil; Participação.

\begin{abstract}
In this article, we analyze the experimentation of the GAM Strategy in Espírito Santo. The participatory intervention research with GAM over the course of five years constituted the assembly of three devices. In the field of mental health for children and adolescents were proposed a GAM Group with family members of children using psychotropic drugs and an Atelier with children. The third device involved the broader mental health network, with the implementation of the GAM Strategy carried out by workers, having the University as a partner with the creation of a Collective supervision device. We dimension this experience as the inaugurator of other areas of GAM intervention, understanding that such opening highlights the potential of this strategy and also its greatest challenge: the ability to be reinvented for each situated experience. Each device created has become inseparable in the construction of participation that makes collectives more co-managing and autonomous.
\end{abstract}


Keywords: Gaining Autonomy \& Medication Management; Mental health; Children's Mental Health; Participation.

\section{Resumen}

En este artículo, analizamos la experimentación de la Estrategia GAM en Espírito Santo. El trabajo de investigación de intervención participativa con GAM en el transcurso de cinco años constituyó el ensamblaje de tres dispositivos. En el campo de la salud mental para niños y adolescentes, se propuso un Grupo GAM con familiares de niños que usan drogas psicotrópicas y un Taller con niños. El tercer dispositivo involucró a la red más amplia de salud mental, con la implementación de la Estrategia GAM llevada a cabo por los trabajadores, teniendo a la Universidad como socio desde la creación de un dispositivo de Supervisión colectiva. Dimensionamos esta experiencia como el iniciador de otras áreas de intervención de GAM, entendiendo que tal apertura resalta el potencial de esta estrategia y también su mayor desafío: la capacidad de reinventarse para cada experiencia situada. Cada dispositivo creado se ha vuelto inseparable en la construcción de la participación que hace que los colectivos sean más cogestivos y autónomos.

Palabras clave: Gestión Autónoma de la Medicación; Salud Mental; Salud Mental de los Niños; Participación.

\section{Introdução}

A operação com a Estratégia da Gestão Autônoma da Medicação (GAM), na relação com a Universidade Federal do Espírito Santo (UFES), teve início em 2013, envolvendo um grupo de pesquisadores composto por duas professoras do Departamento de Psicologia e do Programa de pós-graduação em Psicologia Institucional, graduandos de Psicologia e mestrandos do Programa de pós-graduação. $\mathrm{O}$ trabalho de pesquisa intervenção participativa com a GAM (Passos, Kastrup \& Escóssia, 2009), no percurso de cinco anos, constituiu três frentes de investimento com a montagem de três dispositivos: dois deles situados no campo da saúde mental infantojuvenil: Um Grupo GAM com familiares de crianças que fazem uso de psicotrópicos e uma Oficina com crianças, em uso de medicação. A terceira frente de investimento envolveu a rede de saúde mental mais ampla, com a implementação da Estratégia GAM efetuada por trabalhadoras(es), tendo a Universidade como parceira. Nessa frente de trabalho, a pesquisa se tornou pesquisa apoio a partir de um dispositivo de Supervisão coletiva realizado na Universidade, no encontro entre pesquisadoras(es) com trabalhadoras(es) de Centros de Atenção Psicossocial da rede de saúde mental da região da Grande Vitória. Ainda que os três dispositivos comportem 
especificidades, têm como fio comum a vinculação à Estratégia GAM, exercitando seus princípios de modo situado a cada proposta, serviço e contexto.

Neste artigo, compartilhamos os percursos e problematizações da experimentação da Estratégia GAM no Espírito Santo no acompanhamento dos seus três dispositivos. Dimensionamos essa experiência como inauguradora de outros domínios de intervenção da GAM, especialmente no que toca a saúde mental infantojuvenil, compreendendo que tal abertura coloca em relevo o potencial desta estratégia e também o seu maior desafio: a capacidade de ser reinventada a cada experiência situada. Construir aberturas da/com a GAM nos indica que a diretriz dessa Estratégia é produzir aberturas lá onde as saídas parecem estar obstruídas. Nesse sentido, o texto percorre as singularidades que $\mathrm{o}$ processo $\mathrm{de}$ apropriação, exercício e reinvenção da GAM assumiu no Espírito Santo, ao ser estrategicamente reposicionado em situação.

A Construção de um Trabalho Participativo Com Crianças no ES, Tendo Como Direção a Estratégia GAM

Em 2013, o grupo de pesquisa (UFES) iniciou uma parceria com o Centro de Atenção Psicossocial Infantojuvenil,
CAPSi de Vitória, propondo inicialmente um grupo de intervenção GAM com familiares (GIF) de crianças que faziam uso de Ritalina (Domitrovic, 2014, Caliman, Passos \& Machado, 2016, Caliman, Peterle \& César, 2017). O GIF no CAPSi foi o primeiro e mais antigo dispositivo construído na relação com a GAM no Espírito Santo. Cerca de um ano depois, em 2014, iniciamos a criação da oficina com crianças. Analisar esse percurso de trabalho, no entanto, solicita ressaltar alguns aspectos que marcam a singularidade do trabalho na saúde mental infantojuvenil, a importância da experimentação da GAM neste campo e do exercício da participação.

Quando falamos da proposição da GAM no Brasil, ressaltamos que a questão do uso de psicotrópicos é um ponto nevrálgico da reforma psiquiátrica, na medida em que a prescrição de medicamentos continua sendo uma prática hierarquizada, não participativa, quase sempre isolada. $\mathrm{O}$ exercício da GAM se dispõe à construção de espaços de partilha nos quais um plano de participação possa ser gerado e sustentado. Por diversos motivos, o ponto nevrálgico que a GAM visa cuidar complexifica-se quando pensamos no campo da saúde mental infantojuvenil. Inicialmente porque, na reforma psiquiátrica brasileira, cuidar da saúde mental de crianças, adolescentes e 
jovens é recente, e mesmo tardio (Couto \& Delgado, 2015). Neste sentido, a própria reforma tem reposicionamentos a viver com esse campo, na medida em que só tardiamente, a partir dos anos 2000, o incluiu em sua agenda. Antes deste momento, as questões relacionadas à saúde mental infantojuvenil ficavam restritas aos setores da educação e assistência social e, não poucas vezes, dispersas em várias instituições como abrigos, orfanatos e educandários. O cuidado com crianças e jovens na saúde mental no Brasil é, portanto, marcado por uma fragmentação histórica, desafiadora em sua reversão. A intersetorialidade, princípio estruturante na organização da rede de cuidado em Saúde Mental infantojuvenil, apresenta-se como um dos grandes desafios dessa política, exigindo a criação de mecanismos de conversa e produção de práticas e saberes coletivos.

Mas, além do desafio da construção de um trabalho efetivamente intersetorial, há aquele vinculado à construção de uma outra política da infância. Definida quase sempre como um momento da vida cuja fala é subestimada ou mesmo recusada, a infância é historicamente marcada pela incompletude e imaturidade. Quando pensamos na criança que recebe um diagnóstico de transtorno mental, usuária de instituições de saúde mental, que faz uso de psicotrópicos, percebemos que a relação de desqualificação quanto à sua participação pode ser ainda mais intensificada. A criança é duplamente objetificada: pelo estigma do adoecimento e pela infantilização sofrida por ser criança. $\mathrm{O}$ efeito dessa dupla desqualificação é a geração de tutela. Muitas crianças não compreendem porque frequentam um serviço de saúde mental, não participam das decisões em relação a seus processos de tratamento, não sabendo, inclusive, que fazem uso de medicamentos.

$\mathrm{Na}$ saúde mental, identificamos, portanto, uma política da infância caracterizada por uma dupla ausência da criança. Nos discursos e práticas sobre ela, a criança surge como um sujeito marcado pela falta e pelo déficit. Mas além dessa falta ou ausência na criança, podemos dizer que ela está ausente, não participando dos processos de decisão e negociação que lhe dizem respeito e da construção dos saberes sobre ela. Como, então, incluir o saber do usuário que é criança? Como torná-la mais atuante e participativa nas decisões sobre o tratamento, nas relações tecidas com os familiares, profissionais de saúde, professores?

Diante dessas questões, o trabalho com a estratégia GAM no campo infantojuvenil nos levou a pensar na encarnação de seus princípios basilares Cogestão e Autonomia - na relação com outro princípio: o da Participação. Em 
nosso trabalho, a participação foi, sem dúvida, um dos exercícios fundamentais para a geração de autonomia e cogestão com crianças. Primeiramente, portanto, era necessário afirmar a prerrogativa do Direito à Participação.

O Direito à Participação é um dos princípios da Convenção Internacional sobre os Direitos da Criança, promulgada pela Organização das Nações Unidas (ONU) em 1959. Nesse documento, a participação diz respeito à expressão da opinião da criança e o direito a voz em processos judiciais e administrativos. No entanto, para Fernandes (2016), o exercício da participação não significa permitir que as crianças falem, mas “deve ser uma ação dotada de sentido para o sujeito, e que tenha implicações; implicações em termo de transformação social” (p. 188). Ou seja, para além da inclusão da voz infantil, a participação demanda uma abertura dos grupos nos quais a criança se insere para que possam efetivamente escutá-la, considerar o que diz como legítimo, tendo assim impacto sobre o grupo.

Ao relacionarmos a saúde mental infantojuvenil e o problema da participação algumas interrogações se colocam: O que é participar? Como participa a criança cujas formas de expressão encontram-se obstacularizadas ou fragilizadas? Muitas crianças chegam aos CAPSi(s) e a outros serviços da rede de saúde mental objetificadas, marcadas por relações de violência e descuido, encarnando em suas falas e ações o lugar do déficit. O deslocamento deste lugar de objetificação requer uma ampliação do conceito de participação e do próprio exercício participativo, visando incluir neles expressões mais sutis.

Essas preocupações guiaram $\mathrm{o}$ percurso de trabalho com a GAM no CAPSi de Vitória ao longo de 5 anos de atuação. Com a estratégia GAM e a sua abertura a este novo campo, nos desafiamos a lidar com a fragmentação que marca as práticas de cuidado em torno da saúde mental infantojuvenil, a dupla ausência da criança e o desafio do cultivo de processos participativos, através dos quais a cogestão e a autonomia pudessem ser experimentadas.

\section{Dispositivo: O Grupo GAM com Familiares (GIF) de Crianças}

Até 2013 apenas um grupo de intervenção GAM com familiares (GIF) havia sido criado no Brasil, em São Pedro da Aldeia, no Rio de Janeiro. Estávamos propondo o segundo grupo GAM com familiares, mas neste caso, familiares de crianças usuárias de um CAPSi. Se o trabalho com os familiares de adultos na construção da cogestão autônoma da medicação mostrava-se importante, na 
medida em que é a família que na maior parte das vezes faz a gestão do tratamento (Renault, 2015), a saúde mental infantojuvenil apontava ser fundamental a inclusão do familiar no processo de cuidado. Como nos diz Couto (2012), a rede mínima que precisa ser tecida na saúde mental de crianças e adolescentes deve partir da inclusão do familiar - que é quem media o contato da criança com todas as demais instituições, define as trajetórias de cuidado e é o tempo todo responsabilizado por esse cuidado. Assim, atentos aos desafios que bordeiam o campo da saúde mental infantojuvenil e à necessidade da construção de outra política da infância na direção participativa, percebíamos a importância do cultivo de uma rede mínima que tivesse como ponto de partida os familiares. E, nesse trabalho, do exercício de abertura ao próprio saber e experiência da criança.

A relação da pesquisa com o GIF criado no CAPSi viveu modulações importantes ao longo do trabalho. Como pesquisadores da UFES, participamos do GIF entre dezembro de 2013 a novembro de 2016. Após esse tempo, mantiveram-se presentes estagiários de psicologia, sob orientação das professoras pesquisadoras. Com a saída dos pesquisadores do GIF, os trabalhadores do CAPSi que operavam o manejo com o grupo GAM começaram a participar do dispositivo de supervisão coletiva na UFES. O GIF no CAPSi teve sua finalização no final do ano de 2018. Foram, então, 3 anos de trabalho especificamente com a presença da Universidade no GIF, de encontros semanais dos quais participaram 21 mães, avós, tias, diferentes profissionais do CAPSi e pesquisadores da UFES. Um grupo GAM que, como veremos, também teve a participação de crianças.

Em sua duração, o trabalho com o GIF no CAPSi possibilitou alongar-se no tempo, acolhendo movimentos de idas e vindas de familiares e profissionais, sustentando um espaço para demorar-se sobre questões que demandavam tempo para pensar. Neste artigo, abordaremos especificamente

dois movimentos/aberturas importantes, cultivados na duração do GIF: o acesso e inclusão da experiência infantil e do familiar. Estes movimentos/aberturas podem ser definidos como um processo contínuo de sustenção de um plano de participação entre nós.

\section{Primeiro Movimento/abertura: Acesso e Inclusão da Experiência Infantil}

$$
\text { O desafio inicial do grupo GAM }
$$
com familiares era cultivar um espaço coletivo no qual a experiência infantil pudesse ser acessada e efetivamente ouvida - Deixar de ser ausente podendo, 
portanto, participar. Nos primeiros meses essa foi a direção do trabalho. Começamos com a sugestão de responder as perguntas do Guia como se "fôssemos as crianças" que freqüentavam o CAPSi. Esse exercício era também proposto aos profissionais que participavam do grupo. Quando o familiar ou o profissional respondia como se fosse a criança inaugurava-se a possibilidade do deslocamento de seus pontos de vistas (Gaigher, 2018), produzindo um alargamento das versões sobre as experiências partilhadas. Ao mesmo tempo, muitos familiares ao se perguntarem como a criança responderia às questões propostas pelo Guia GAM perceberam que "era difícil dizer por elas, pois elas pensam diferente, de uma forma diferente". Perceber que a criança tinha uma forma de dizer diferente (e não desqualificada) foi um passo fundamental. $\mathrm{O}$ que era essa diferença? $\mathrm{O}$ que ela nos dizia? O que provocava em nós?

Este foi um primeiro movimento de curiosidade e interesse pelo dizer infantil que fez com que muitas mães, em casa, fizessem as perguntas do guia diretamente para as crianças. A partir deste momento, o grupo começou a ser ocupado pelas falas e experiências das crianças, mas também e talvez mais fundamentalmente, pela experiência de encontro e conversa entre mães, crianças e profissionais, mediada pelo uso do Guia. Assim, as conversas iniciadas no GIF eram prolongadas em casa com as crianças e vice versa: as surpresas, espantos, incômodos vividos na conversa com as crianças eram trazidos para o grupo, gerando um efeito de ressonância extremamente potente, em uma direção que ampliava o plano de participação.

Avaliando o percurso do grupo GAM no CAPSi, percebemos que foram muitas as questões que se tornaram assunto de conversa com as crianças em casa e que eram posteriormente partilhadas no grupo. $\mathrm{Na}$ medida em que a criança deixava de estar ausente, ou fazia-se presente, tornava-se possível equivocar e deslocá-la do lugar do déficit, daquele cujo saber é sempre faltoso. Fomos, portanto, operando com essa circularidade. Cultivar um espaço de escuta e acolhimento sensível à experiência infantil e permitir que ela participe efetivamente possibilita que a criança surja com outros contornos, não desqualificantes. Outra política da infância tornava-se operante.

Desde o início, o grupo GAM com familiares optou por ser um grupo aberto. E essa mesma abertura produziu modulações importantes na constituição do grupo. Os familiares que freqüentavam o GIF eram mães, avós, tias, mas a partir de certo momento também crianças, irmãs ou primas de crianças usuárias do CAPSi que eram convidadas a participar do grupo. 
Afinal, era um grupo de familiares. Incrivelmente, foi uma intervenção em todos nós perceber que crianças são também familiares que cuidam, acompanham, vivem cotidianamente os dilemas e controvérsias em torno da medicação. Já na conversa em casa com as crianças usuárias do CAPSi sobre suas redes de apoio, outras crianças parceiras e amigas surgiam em suas falas. No desenho de Pedro sobre sua rede de apoio, o irmão Paulo surge mais próximo dele do que outros cuidadores (1). Para espanto da mãe, mais próximo do que ela mesma. A criança cuida. Esse foi um grande deslocamento de ponto de vista no grupo: perceber a criança como cuidadora, participante ativa de uma rede de apoio. E a criança usuária do CAPSi, cuida? Como ela se cuida? A conversa disparada pela questão do cuidado evocada no segundo passo do Guia GAM atravessou muitos encontros do grupo, alimentando o movimento de reposicionar a ausência na criança e a percepção de que ela pode pouca coisa.

$\mathrm{O}$ relato dos familiares falava de uma vida cansada. Durante muito tempo, compartilhou-se a dificuldade de sempre ter que sozinha dar conta de tudo, sofrer os processos de culpabilização e responsabilização. Efeitos das redes de apoio esburacadas e fragilizadas, da ausência de intersetorialidade no cuidado.
Efeitos também de um cuidado tutelar, baseado na sobreproteção (Ferreira, 2016). Era preciso perceber e permitir que a criança participasse da tecitura de suas redes de apoio. Assim, na medida em que o próprio grupo se fortalecia como espaço de apoio e a rede aos poucos se ampliava, povoada inclusive por crianças, tornava-se possível construir uma outra política da infância, um outro lugar para a criança usuária. E foi importante perceber que a partilha do cuidado e a construção de uma vida mais autônoma para a própria família dependia também de um reposicionamento do familiar em relação à criança. Paradoxalmente, quando a criança participa, torna-se ativa no grupo, deslocando a política da infância dominante, este reposicionamento permite que o grupo cuide de outras questões. Em certa medida, a criança deixa de ser o foco do problema, criando espaço para que a experiência do próprio familiar seja mais cuidada, ouvida, acolhida. A partir desse momento, a GAM passa por uma nova abertura.

\section{Segundo Movimento/abertura: Acesso e Inclusão da Experiência do Familiar}

Em meados de 2016 a relação com o uso do guia GAM no GIF sofre muitas variações. $\mathrm{O}$ acompanhamento de seus passos em ciclos já repetidos dá lugar mais 
intensamente a outras ferramentas, pois outras questões pediam passagem.O desejo era de olhar com mais calma para aquilo que atravessava aquelas mães/mulheres quando não estavam cuidando de suas crianças. O que mais se passava com elas que, inclusive, atravessava também a experiência de cuidar? Começamos, então, a olhar para aqueles corpos que no exercício da proteção contínua precisaram fazer-se bélicos e armados para literalmente lutarem pelos direitos de suas crianças (Selvatici, 2017). Foi preciso legitimar um espaço de cuidado e acolhimento da experiência de acompanhar e cuidar de uma criança usuária da saúde mental. E mais ainda: pensar no familiar como usuário da rede de saúde mental infantojuvenil, cujo saber e experiência precisam ser acolhidos, legitimados, cuidados. Foi preciso, portanto, estar atento ao exercício de participação que alcançava o familiar.

$\mathrm{Na}$ experiência do familiar uma questão que comparecia para as participantes era a de se saberem não apenas como mães, mas mulheres. Foi então que se ousou a abertura do fazer grupal, construindo juntas outros dispositivos de expressão (técnicas grupais, leituras de histórias, escritas, poemas). Com a produção de cartas cuidamos também da relação estabelecida com a escola, com a comunidade e com o serviço (Chaves, 2016; Chaves \& Caliman, 2017). Neste momento do trabalho, fomos também acolhendo no grupo as próprias crianças usuárias do CAPSi, chamadas por nós de "filhos da GAM". Nova abertura dessa estratégia. Um movimento espontâneo das próprias mães que, vez ou outra, convidavam os filhos a partilharem alguma experiência com o grupo e também das crianças que, estando no Capsi, acabavam por se achegar ao GIF. A presença das crianças era acolhida e ouvida em suas experiências e singularidades, assim como a própria experiência de acompanhar e cuidar de uma criança usuária de um CAPSi. Como compartilhou uma familiar, naquele espaço onde "podíamos falar sem ser julgados, onde não precisávamos estar armados e prontos para a briga", acompanhamos o GIF grupo de intervenção com familiares, constituir-se também como um GIFU grupo de intervenção com familiares e usuários crianças, afirmando o potencial da conversa e das experiências de partilha respeitosa.

\section{Dispositivo: Oficina com Crianças}

No segundo semestre de 2014, iniciamos o desenho de um trabalho especificamente com crianças direcionado pela Estratégia GAM. Começamos a fazer visitas semanais ao CAPSi de Vitória para 
vivência do cotidiano do serviço e contato mais direto com as crianças que o frequentavam. Além disso, realizamos oito encontros com um Grupo de Trabalho (GT) do qual participaram profissionais do CAPSi e pesquisadoras. O GT buscava pensar as possibilidades e dificuldades do uso do Guia GAM com o público infantojuvenil. Esta etapa inicial possibilitou a construção de um trabalho situado, que considerasse as particularidades, necessidades e demandas do serviço, bem como dos seus usuários.

Os encontros com o GT evidenciaram pistas metodológicas importantes. Quanto mais pensávamos na reformulação das questões do Guia GAM para o trabalho com crianças, mais se explicitava a dificuldade de somente adaptá-las, utilizando o Guia como pensado para o público adulto. Compreendíamos que a direção cogestiva da Estratégia nos era fundamental, mas que não poderíamos usar o Guia da mesma maneira, em grupos de conversação. O trabalho com o infante exigia a criação de um dispositivo brincante, necessariamente inventivo e aberto à experimentação (Caliman et al., 2018). Desta inquietação nasceu, portanto, a Oficina da Palavra. Ao longo da experimentação com a Oficina da Palavra, no entanto, uma outra modulação foi gerada. Tratava-se não apenas de realizar uma oficina com crianças, mas de

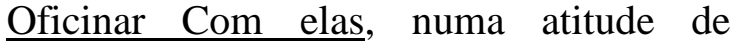
usinagem e de invenção dos recursos, matérias e modos de experimentá-la, aliada a um Oficinar Com a GAM, reinventando a estratégia com esse público. Era importante um trabalho com as crianças para sentir e perceber de que modo, de fato, a estratégia se atualizaria. Um pesquisarCOM crianças e não SOBRE crianças (Moraes, 2010).

Assim, a direção de gestão coletiva e participativa preconizada pela GAM esteve presente desde o início da elaboração da Oficina da Palavra. Durante as visitas ao CAPSi e no trabalho com o GT, pactuou-se que a indicação e convite das crianças/adolescentes para a oficina deveria acontecer em conjunto com os profissionais da instituição. Foi também acordado que a Oficina deveria fazer parte do Projeto Terapêutico Singular (PTS) da criança e que um profissional de referência acompanharia o trabalho. Em março de 2015, começava a Oficina da Palavra, realizada às quartas-feiras pela manhã, durando cerca de uma hora, contando com a presença de nove crianças entre 8 e 15 anos, um profissional do CAPSi e três oficineiras, estudantes do curso de Psicologia da UFES. A Oficina finalizouse em dezembro de 2017. A maior parte das crianças esteve vinculada ao dispositivo do início à finalização do processo. Além de usuárias da rede pública 
de saúde mental da cidade de Vitória, eram crianças negras, em sua maioria, moradoras de periferias, que faziam uso de psicofármacos.

\section{Primeiro Movimento/abertura} Oficinar a GAM Com Crianças

A experimentação da Estratégia com crianças impunha desde o início um desafio político-metodológico. Como oficinar a GAM com crianças? Como estar comcrianças quando se diz que são incapazes de participar, de estar em grupo, de se engajar em atividades e compor relações? Como estar com crianças em uma oficina, transformando a prerrogativa histórica de que elas têm pouco a dizer?

A Palavra que dá direção à Oficina (Oficina da Palavra) não é trivial. Ela indica uma orientação do trabalho diante da dupla ausência sofrida pela criança em uma política da infância dominante. Porém, não se trata da Palavra da opinião simplesmente. Sequer compareceu, por vezes, como palavra falada. Observamos, inclusive, que a super valorizaçãoda linguagem verbal como modo de relação com as crianças pode tornar-se um limitador. Há experiências que não passam pelo domínio de um relacionar-se verbal (Stern, 1992). Tratava-se, então, de incluir e fazer participar outros mundos - aqueles das infâncias. A experiência da oficina foi ressaltando que as crianças encontram modos improváveis de Palavra, performatizando mais que verbalizando o que sentem e o que desejam.

Além disso, no oficinar a GAM com crianças encontrávamos um desafio central: Como acessar a experiência com o uso de medicamentos? Como gerar na oficina uma prática problematizadora dos processos de medicamentalização que na atualidade incidem fortemente sobre os corpos infantis? Um dos modos de organizar a direção do trabalho na oficina foi compreender, a partir do estudo dos Guia GAM do Usuário e do Moderador que a Estratégia GAM visa cultivar o estabelecimento de outra relação com o uso de psicofármacos, considerando seus efeitos em todas as dimensões da vida daqueles que deles fazem uso. Compreendíamos, portanto, que para acompanhar com as crianças a experiência com o uso de psicofármacos era importante acessar com elas as dimensões e complexidades que atravessam suas experiências de vida. $\mathrm{O}$ oficinar exercitou a invenção de modos de acesso à experiência que as crianças faziam delas mesmas, utilizando para isso recursos diversos e tendo o dispositivo grupal como plano primordial de trabalho (Caliman et al., 2019). No percurso de trabalho perguntávamos: Quais processos de produção de vida e adoecimento 
atravessam estas crianças e adolescentes? Quais modos de expressão são possíveis? Quais são suas relações com o uso de medicamentos e com a experiência de ser diagnosticado com um transtorno mental?

Quanto ao dispositivo grupal nos dispúnhamos a construir a experiência de Grupalidade em sua função de gerar pertencimento ao grupo, mas, sobretudo, de performatizar a base relacional que nos é constituinte (César, 2008). Acessar a grupalidade era também manejar com os modos de relação que as crianças constroem entre elas (com os profissionais, oficineiras, familiares, com o abrigo, com o CAPSi, etc.), sendo a relação a matéria de trabalho com que se oficinava. No manejo e exercício com um plano de grupalidade tecia-se uma política da infância Não Infantilizadora, construída na relação com as crianças como legítimos participantes.

No primeiro ano da oficina, por exemplo, acompanhamos durante meses os movimentos de Gabriel (criança da oficina) saindo da sala onde a oficina acontecia, a cada vez que não concordava com algo que se passava ou quando se sentia contrariado, agredido, perturbado pelo encontro com o grupo. O infantilizar pode assumir muitas formas nessa experiência, como ver o movimento da criança como birra e “deixar prá lá" para ver se "a criança se acalma".
Diferentemente, uma prática frequente na oficina era ir ao encontro dessa criança, que estava por vezes em lugares não imaginados: em cima da árvore no pátio, na mureta do canto da saída do CAPSi, debaixo do tanque, trancado no banheiro.

Muitas vezes, nessa situação, Gabriel não falava e não voltava à oficina. No entanto, quando alguma oficineira se aproximava, perguntando se poderia fazer companhia e com ele ali ficar, Gabriel aceitava. Em gestos muito sutis, um elo de conversa, de contato, de compartilhamento se sustentava. Sentíamos que alimentávamos nessa hora condições de aliança e vínculo para que, em outro momento, os afetos que o encontro provocava pudessem se performatizar de outras maneiras. Ali também percebíamos que oficinar estava além e aquém de uma sala ou da realização de uma atividade em si.

Os processos de infantilização, atravessados por uma lógica hegemônica do que se considera ser o "normal" em relação a uma criança consolidam a incapacidade de determinados sujeitos participarem de seus processos de cuidado. Esses processos também estavam embutidos em nós adultos: pesquisadoras, oficineiras e profissionais do CAPSi. Não infantilizar e não moralizar a criança não são desafios simples. O cotidiano das oficinas e a relação tecida com os 
participantes apontam um fazer complexo. Trata-se de não infantilizar não apenas a criança, mas especialmente o infante. Não constranger um devir criança (Guattari, 1981), que atravessa o sujeito criança e também o adulto.Por isso, o exercício da não infantilização exige um risco diante do abandono do controle sobre a atividade e sobre as relações, contingenciando resoluções fáceis. Há uma radicalidade da alteridade na infância que, por não ser suportada, é também sufocada. Não sufocar o infante em nós era o exercício diário que nos abria à invenção.Nesse exercício a cogestão era o princípio norteador. Não infantilizar as demandas, as questões surgidas e os movimentos inventados era um processo chave para a participação, que permitia cogerir os mais diferentes processos com as Crianças.

\section{Segundo Movimento/abertura - O Cogerir Com Crinças e o Êthos da Conversa}

Um movimento importante gerado na oficina foi a experimentação da conversa.Recorrentemente íamos ao encontro da criança, perguntávamos o que acontecia, interessávamo-nos por como ela via e sentia o que se instalava. Conversávamos. A cena de um diário traz um desses momentos que dizem da possibilidade de dialogar e debater com a oficineira que procura a criança para saber o que se passava:

Gabriel (criança) começou a gritar "louco, ele me chamou de louco!!!". Meiri (oficineira) e Renata (profissional do CAPSi) tentavam explicar para Gabriel que ninguém havia dito que ele era louco, mas Gabriel não parecia entender. Depois disso, Leo (criança) foi até o quadro onde Gabriel tinha desenhado todos nós e escrito "meus amigos" e escreve "meus amigos doidos". Gabriel continua gritando e falando muitas coisas, até que se sentou de costas para o grupo, com o rosto virado para a parede. Meiri pediu que ele contasse para o grupo o que estava sentindo e, para minha surpresa (oficineira), ele falou mesmo. Me surpreendi muito com essa atitude dele de trazer para o grupo o que estava pensando e me surpreendi também com as reações das outras crianças. Muitas vezes, quando acontece algo, Gabriel sai da sala e conta o ocorrido apenas para a pessoa que vai atrás dele e foi muito bonito ver ele sustentando isso ali, no grupo, falando do que sente (Diário de campo, 13/04/16).

A surpresa da oficineiraé partilhada também pelos outros participantes, pois Gabriel faz agora o exercício de colocar aos outros participantes o que sente. Essa possibilidade foi construída no fio de conversa sustentado durante muitos encontros anteriores, nos quais se negociava com ele posições e pontos de vista, em que um vínculo de confiança e 
participação era gerado. Gabriel expressa seus afetos mais aflitivos - "que ninguém gosta dele", "que ele quer morrer" - E isso se dá, o que não é trivial, no mesmo dia em que declarou seus afetos de amizade em relação ao grupo, escrevendo no quadro: "meus amigos". Um dia no qual eram partilhadas experiências difíceis vividas também pelos outros participantes: o estigma das palavras "louco" e "doido" que recaíam tanto sobre Gabriel quanto sobre as outras crianças. Às vezes, para implicar um com o outro chamavam-se de “débil mental” enunciando aquilo que já teriam ouvido sobre si ou pressentido na relação estabelecida com eles. O que gerava reações as mais diversas, um gatilho para afetos aflitivos, mas também de resistência à desqualificação que o chamamento gerava.

A conversa foi se tornando nosso modus operandi por excelência, que exercitava o rompimento com dois movimentos que desafiam as experiências participativas e cogestivas: decidir pelo outro, não incluindo-o; ou abandoná-lo, deixando-o só na tomada e sustentação de uma posição solitária e independente. Ao contrário, conversar implica os sujeitos nas questões, nos acontecimentos e seus destinos, mas sem retirar-se, gerando uma composição. Trata-se, portanto, de cogestão. A cogestão surgia na oficina como um êthos (Selvatici, 2017), sustentado no conversar, entendendo que o atrevimento à conversa com crianças e a acolhida da improvisação necessária, das movimentações inquietas, das pactuações e repactuações com estas acaba por produzir transformação em todos. Nesse cenário, a conversa comparecia como uma prática de cuidado e também como uma dimensão mais sutil da cogestão, onde as modulações subjetivas aconteciam.

Ao longo da Oficina fomos compreendendo que a cogestão como conversa (não realizada todo o tempo em palavras) gerava participação e estava presente em muitas operações: $\mathrm{Na}$ montagem e desmontagem da oficina, inicialmente realizada pelas oficineiras e profissional e que depois vai incluindo as crianças efetivamente; na dimensão dos combinados e pactuações que se abrem às propostas e desejos das crianças e que fazia com que a oficina cada vez mais se transformasse, solicitando improvisação contínua; na inclusão dos movimentos os mais inusitados que faziam com que vários objetos fossem sendo acolhidos no encontro, no modo como se lia os livros ou se contava as histórias.

\section{A Propagação do Trabalho Com a GAM no CAPSi}

É importante apontarmos os modos através dos quais, no trabalho com a 
estratégia GAM no CAPSi, fomos acolhendo o exercício ético de não fazer do trabalho com a GAM uma ilha no serviço. Compreendíamos que por ser proposto pela Universidade e acolher nele estudantes havia sempre o perigo de ser transformado em um dispositivoà parte do serviço. Os modos de enfrentamento em relação a isso eram sempre de compartilhar o trabalho realizado nos encontros e espaços que envolviam outros grupos e profissionais do serviço.

Para o GIF, a primeira propagação ocorreu por uma demanda vinda diretamente dos familiares. Após a construção da primeira narrativa e realização do grupo narrativo, foi sugerido que o que construímos ali no espaço grupal pudesse ser partilhado na reunião de equipe do CAPSi. Para aquelas mães/mulheres, mas também para os profissionais que integravam o grupo, era importante que a experiência do grupo GAM extrapolasse as paredes da sala na qual nos reuníamos, produzindo outros efeitos na instituição. Assim, a partir deste momento, após cada narrativa produzida e analisada no GIF, a mesma era partilhada e discutida nas reuniões de equipe, produzindo efeitos extremamente potentes, além de inquietações e incômodos nem sempre fáceis de lidar. Como resultado desta propagação outros encontros foram gerados nos quais temas e experiências prolematizadas nas narrativas puderam receber mais atenção, prolongando a conversa entre familiares, profissionais do CAPSi e pesquisadores.

Para a oficina da palavra, a operação de propagação da GAM era especialmente importante, por estar incluída no PTS das crianças. Como a grande maioria dos profissionais de referência não participava da oficina era preciso encontrar formas de partilhar $\mathrm{o}$ trabalho realizado. Assim, a oficina se ampliou de modo a gerar encontros com outros profissionais, participando de reuniões de equipe no CAPSi e de encontros de profissionais de referência. Além disso, durante o último ano da oficina foi garantido um tempo de supervisão coletiva e planejamento desse dispositivo no próprio CAPSi. Foram também realizados encontros com os familiares das crianças e uma oficina com os mesmos, de modo a acessarem na própria experimentação o desconcerto do devir criança. Também experimentamos visitas com os profissionais do CAPSiàs escolas de algumas das crianças para conversas sobre demandas surgidas e problematização das mesmas, além de visitas e conversas no abrigo onde vivia uma criança em acolhimento institucional. 
Dispositivo: Supervisão Coletiva Com Trabalhadoras(es)

Em maio de 2014 a pesquisa organizou um seminário intitulado "A experiência do uso de psicofármacos: desafios para a política de saúde mental infantojuvenil", na UFES, que contou com a participação de professores e pesquisadores (UFES), colaboradores de outras universidades do Brasil e profissionais e usuários da rede de saúde mental de Vitória (Domitrovic, 2014). A partir deste seminário, alguns profissionais da rede de saúde mental tiveram acesso à experiência da GAM. Como desdobramento, uma demanda se constitui por grupos de estudo e discussão, além de supervisão para experimentação da Estratégia em alguns serviços. Em maio de 2015 foi realizado um primeiro encontro com alguns profissionais da rede de saúde mental de três municípios da Grande Vitória interessados na GAM.

Sem dúvida, são muitos os fios que movem a pertinência da Estratégia GAM para as(os) trabalhadoras(es) da rede de saúde mental no ES. Mas, acreditamos encontrar algumas pistas no aspecto situacional que constitui a Rede de Atenção Psicossocial (RAPS) no estado. O Espírito Santo, localizado na região sudeste do Brasil, é constituído por 78 municípios, de pequeno porte, abarcando uma população total de 3,97 milhões de habitantes (IBGE, 2018). Quanto ao modelo de atenção em saúde, historicamente pautou-se em grandes hospitais psiquiátricos públicos e privados. Foi somente no final da década de 1990 que o estado se colocou de modo mais efetivo no contexto da reestruturação da assistência psiquiátrica, tempo em que se encontrava quatro hospitais psiquiátricos (assentados na lógica manicomial), que absorviam a enorme demanda por cuidado (internação). Segundo dados do Ministério da Saúde, do ano de 2015, até 2014 o Espírito Santo era avaliado como tendo uma baixa cobertura de CAPS, com: 10 CAPS I, 07 CAPS II, 01 CAPSi, 05 CAPSad, e sendo um dos três estados (além de Rondônia e Mato Grosso) que ainda não possuía serviços 24h (CAPS III ou CAPSad III) habilitados (BRASIL, 2015). O ES configurava-se como o estado da região sudeste com a menor cobertura de CAPS habilitado por município elegível.

Sem a intenção de incorrer em generalizações, tais dados apontam uma história recente de estruturação do cuidado em saúde mental a partir da lógica antimanicomial e parecem dialogar com as conversas tecidas no dispositivo da supervisão coletiva, em que frequentemente as(os) trabalhadoras(es) partilhavam os desafios da sustentação da 
desinstitucionalização e de um outro modelo de atenção quanto ao cuidado. Portanto, o que move o encontro entre pesquisadoras, profissionais e a estratégia GAM no ES parece ser um movimento de resistência vivo neste estado, diante de muitos retrocessos vividos. É como dispositivo que pode fortalecer a resistência em relação à experiência de precarização e assujeitamento que o encontro em supervisão, que se faz coletiva, afirmou-se. E é nessa articulação que a GAM no ES surge efetivamente como uma estratégiaque auxilia no reposicionamento da política de saúde mental e no seu acordar cogestivo, participativo, de afirmação da experiência do apoio e da autonomia.

Os encontros que tiveram início no ano de 2015 na universidade incluiram as pesquisadoras professoras e um grupo de profissionais do município de Serra (CAPS II). Nestes encontros, realizava-se a leitura e discussão do Guia do Moderador, além do diálogo sobre as questões que compareciam quanto a uma possível implementação do Grupo de Intervenção GAM com Usuários (GIU). De 2016 a 2018, os encontros de supervisão aconteceram com regularização quinzenal e a participação foi ampliada quando trabalhadoras(es) de três municípios integram o trabalho. Nesse processo, são implantados um GIU no CAPS II/Vitória, dois GIU no CAPS II/Serra, um GIF no CAPSi/Serra, e grupos de estudo com moderadores no CAPS AD/Vila Velha, além da continuação do GIF já existente no CAPSi/Vitória. Em 2017, profisionais do GIF do CAPSi passam a integrar a supervisão. Participaram de modo contínuo e/ou pontualmente diferentes profissionais: assistentes sociais, enfermeiros, farmacêuticas, médicas, educadores físicos, psicólogos, terapeuta ocupacional, psiquiatras e uma técnica de enfermagem.

Foram quase quatro anos de encontros frequentes e sustentados não sem dificuldade, posto que cada trabalhador gerava esforços na negociação de disponibilidades, liberações e deslocamentos, delineando os caminhos de uma ampliação da Estratégia GAM no ES. Vale lembrar que essa ampliação não partiu de uma negociação/apresentação da proposta da pesquisa aos gestores/coordenadores de saúde mental, como ocorreu em outros estados brasileiros. O "encontro", "grupo de estudos", como inicialmente era chamado por nós, foi modulando-se de modo que o grupo acaba por nomeá-lo como "supervisão". Compreendíamos a inexistência dos espaços de supervisão e da contratação de supervisores para os CAPS no estado. Porém, a supervisão coletiva que púnhamos juntos a funcionar distinguia-se mais como uma co-visão, 
onde a dimensão coletiva da experiência abria-se na circulação da palavra, na produção de perguntas uns para os outros e equivocação de respostas. Aberturas da GAM.

A supervisão coletiva como dispositivo observava os princípios da GAM - autonomia e cogestão, operando uma experiência de rede de apoio entre profissionais no exercício diário com a GAM com usuários e familiares. As tardes de encontro moviam-se em uma atmosfera de acolhimento, suporte e afetuosidade. Além da leitura conjunta do Guia dos Moderadores GAM, a supervisão trabalhava com a partilha do que se passava nos grupos GAM nos serviços. Desde o início, acompanhou-se os desafios vividos na construção dos grupos: os impasses gerados pela desconfiança de trabalhadores que pensavam que as medicações seriam suspensas com a proposta do trabalho; as dúvidas de quem não se sentia exatamente "preparado" para "manejar". O que seria o manejo? É diferente do que fazemos nos grupos de familiares? O psicólogo sabe manejar melhor do que os outros profissionais? E o que fazer com o usuário que está em crise no grupo? Como fazer com aquele que sai e retorna muitas vezes à roda? Como acolher a pergunta que interpela o diagnóstico? Como não temer que o desejo enunciado por uns (de parar com a medicação) contagie a todos?

O tempo do encontro era dedicado ao acompanhamento dos movimentos vividos, cuidando com os trabalhadores do cuidado que se realizava com os grupos GAM. Mas, sem dúvida, nossa matéria de trabalho por excelência, onde a estratégia GAM (se) movimentava, era o cotidiano de trabalho nos CAPS(s), na política de saúde mental. O que a supervisão recolhia a partir da partilha da experiência com os grupos GAM era a relação entre os colegas, o trabalho com as equipes, a análise dos encaminhamentos realizados, a relação com os usuários, com o território. Os grupos GAM instalados disparavam uma análise dos lugares e pertenças dos profissionais e a relação que cultivavam com o seu trabalho. Por isso, tantas vezes, a supervisão mergulhava em uma análise coletiva dos processos de trabalho neste campo, fazendo-se apoio.

A função apoio como estratégia metodológica encontrou na última década no campo da saúde sua construção e fortalecimento. Visibilizado como tecnologia de gestão capaz de contribuir para a produção de sujeitos autônomos, para a ampliação do coeficiente de corresponsabilidade e construção de relações mais democráticas, tem sido creditada ao apoio institucional a possibilidade de acionar movimentos de 
transformação das práticas de cuidado e dos modelos de gestão e atenção em saúde (César et al., 2014). As experiências de apoio constituídas no âmbito do Ministério da Saúde e das Secretarias Estaduais e Municipais e tendo como base a Política Nacional de Humanização (PNH) no início dos anos 2000 tinham como destino a implementação dos princípios e diretrizes do Sistema Único de Saúde (SUS) e de garantia do direito à saúde. É nessa direção que experiências de apoio e apoiadores frutificaram no país e em diversos serviços de saúde.

Aqui, evocamos a questão do apoio para ampliar essa função que esteve presente no dispositivo da supervisão coletiva e nos Grupos GAM e que é mais que a experiência do suporte ou do "suportar". Em outro contexto de pesquisa, trabalhadores da saúde perguntados sobre o que seria a função apoio enunciam: “apoiar é assoprar, está tudo lá e de forma cuidadosa tem brasa, basta assoprar" (Barros et al., 2014, p. 88). Uma imagem interessante que coloca o apoio em posição de lateralidade, de modo que apoiar não é direcionar, conduzir ou governar. $\mathrm{O}$ apoiador não é aquele que detém a resposta, ou que sabe o caminho. $\mathrm{O}$ que ele produz é um sopro, mas “está tudo lá”. Estar presente, acompanhar o processo de trabalho com outros trabalhadores, disponibilizar-se, sentir a temperatura, assoprar, mas sem tutelar ou fundar-se como centro da roda.

O apoio como exercício metodológico da supervisão coletiva era gerador de análise e aprendizagem, produzia uma dobra na qual quem era apoiado estava ali especialmente porque também realizava apoio, não apenas ao/no grupo de supervisão, mas no espaço de trabalho, nos grupos com usuários. A função apoio circulava e era também com ela que se construia a experimentação da GAM. Apoiando-nos uns aos outros, aquele sopro de problematização, de convite ao reposicionamento e de solidariedade possibilitava encontrar caminhos de resistência. A supervisão como geradora de apoio tinha como um de seus efeitos um fomento da rede de saúde mental e o fortalecimento dos trabalhadores no exercício e ampliação do cuidado.

O envolvimento e articulação de diferentes serviços na supervisão significou uma proposta desafiadora de cuidado, promovendo o encontro com vários profissionais da rede, de diferentes municípios, como forma de fortalecimento ético-político. E, talvez, tenha sido exatamente aí que a GAM pôde gerar sentido e encontrar enraizamento: na sua capacidade de reencantar uma política de saúde mental no cotidiano de trabalho. 


\section{Considerações Finais}

Compartilhamos nesse artigo os encontros construídos entre pesquisadores, trabalhadores, usuários e familiares de equipamentos da rede de saúde mental no Espírito Santo, especialmente da saúde mental infantojuvenil, e a GAM como Estratégia. Buscamos acompanhar as questões e ampliações que emergiram nesses encontros ao reposicionarmos a GAM em favor de um contexto situado e dos desafios de pensar um trabalho $\underline{\text { Com }}$ crianças.

Em situação, no exercício e abertura da GAM, foi possível problematizar a dupla ausência que marca o lugar da criança em seus processos de vida e tratamento, fortalecer a criança e o familiar como atores importantes do cuidado e tecer uma política da infância marcada pela presença da e na criança, pelo seu posicionamento lado a lado, gerado através de diversos movimentos participativos nos quais familiares, crianças, profissionais puderam se reposicionar, surgindo diferentemente. Diante da história de constituição das políticas de saúde mental no Espírito Santo, o exercício da GAM como experiência apoio possibilitou ainda fortalecer uma rede de trabalho com profissionais, que incansavelmente investem na sustentação de processos de desinstitucionalização.

Portanto, Roda COM familiares, Roda COM crianças, Roda COM trabalhadores. Imbricados entre si, cada dispositivo criado tornou-se inseparável na construção da participação, que faz operar coletivos que vão nos permitindo surgir como sujeitos mais cogestivos e autônomos. Especialmente o oficinarparticipativo quanto a saúde mental infantojuvenil apontou desafios pertinentes ao trabalho com a GAM, levando-nos à revisitação do que constitui a direção dessa Estratégia. Em outras palavras, a participação como direção nos proporcionou colocar a GAM em constante experimentação, entendendo que somente assim essa estratégia afirma sua potência: em sua capacidade de ser reinventada a cada experiência situada.

\section{Notas}

${ }^{1}$ Todos os nomes dos usuários e familiares são fictícios.

\section{Referências}

Barros, M. E. B., César, J. M., Gomes, R. S. \& Daros, R. F. (2014). Verbos do apoio institucional: transversalizar, transdisciplinarizar e fortalecer redes de trabalho-vida na saúde. In $\mathrm{R}$. Pinheiro, T. C. Lopes, T. C., F. H. Silva \& A. G. Silva. (Orgs). Práticas de apoio e a integralidade no SUS: 
por uma estratégia de rede multicêntrica de pesquisa (pp. 83 110). Rio de Janeiro: CEPESC/ ABRASCO.

Brasil. Ministério da Saúde. Secretaria de Atenção à Saúde (2015). Saúde Mental em Dados- 12. Informativo eletrônico. Brasília, DF. Recuperado de

https://www.mhinnovation.net/sites/de fault/files/downloads/innovation/repor ts/Report_12-edicao-do-SaudeMental-em-Dados.pdf

Caliman, L. V., César, J. M., Rangel, V. P., Gaigher, L., Simões, A. A. C., \& Fernandes, A. N. (2018). O cultivo atencional como exercício de participação: oficinar com crianças na saúde mental. Ayvu. Rev Psicologia, 05(01), 42 - 66. Recuperado de https://periodicos.uff.br/ayvu/article/vi ew/27401

Caliman, L., Passos, E.\& Machado, A. (2016). A medicação nas práticas de saúde pública: estratégias para a construção de um plano comum. In V. Kastrup \& A. Machado (Orgs.) Movimentos micropolíticos em saúde, formação e reabilitação (pp. 19 - 40). Curitiba: CRV.

Caliman, L. V., Peterle, P. H. S. \& César, J. M. (2017). Gestão autônoma da medicação (GAM) e saúde mental infantojuvenil: experiência de análise e cogestão entre familiares, usuários e profissionais. In A. Leão, J. L. G. Santos \& R. Costa-Moura (Orgs.). Produção de Subjetividade $e$ Institucionalismo: Experimentações Políticas e Estéticas (pp. 10 - 30). Curitiba/PR: Apris Editora.

Caliman, L.V., Rangel, V.P., César, J. M., Partelli, C. M., Simões, A.A. C., Fernandes, A.N, \& Gaigher, L. (2019). Oficina da palavra: literatura, infância e cultivo da atenção. Pesquisa $e$ práticas psicossociais, 14(1), 1 - 13. Recuperado de http://pepsic.bvsalud.org/scielo.php?sc ript=sci_arttext\&pid=S1809$89082019000100009 \& \operatorname{lng}=$ pt\&nrm $=$ is o

César, J. M. (2008). Processos grupais e o plano impessoal: a grupalidade fora no grupo. (Dissertação de mestrado. Curso de Pós-graduação em Psicologia. Universidade Federal Fluminense, Rio de janeiro, RJ).

César, J. M., Barros, M. E. B., Gomes, R. S., \& Daros, R. F. (2014). O apoio como atividade de trabalho: dimensões e desafios para o exercício da função apoio. In R. Pinheiro, T. C. Lopes, F. H. Silva. \& A. G. Silva (Orgs). Práticas de apoio e a integralidade no SUS: por uma estratégia de rede multicêntrica de pesquisa (pp. 139 174). Rio de Janeiro: CEPESC/ ABRASCO.

Chaves, F. A. M. (2016). Articulações entre Saúde Mental e as escolas: pistas para Construir um trabalho intersetorial. (Dissertação de Mestrado.Curso de Pós-graduação em Psicologia Institucional, Universidade Federal do Espírito Santo, Espírito Santo, ES).

Chaves, F. A. M. \& Caliman, L. V. (2017). Entre Saúde Mental e a Escola: A Gestão Autônoma da Medicação. Rev. Polis e Psique, 7(3), 36 - 60. Recuperado de http://pepsic.bvsalud.org/scielo.php?sc ript=sci_arttext\&pid=S2238152X2017000300009

Couto, M. (2012). Política de Saúde Mental para crianças e adolescentes: especificidades e desafios da experiência brasileira (2001-2010). (Tese de doutorado, Curso de Pós- 
graduação do Instituto de Psiquiatria da Universidade Federal do Rio de Janeiro, Rio de Janeiro, RJ).

Couto, M. \& Delgado, P. (2015). Criancas e adolescentes na agenda política da saúde mental brasileira: inclusão tardia, desafios atuais. Psic. Clin., 27(1), 17 - 40. Recuperado de https://www.scielo.br/scielo.php?pid= S0103-

$56652015000100017 \&$ script=sci_abst ract\&tlng $=\mathrm{pt}$

Domitrovic, N. (2014). As práticas farmacológicas com o metilfenidato: habitando a fronteira entre o acesso $e$ $o$ excesso. (Dissertação de mestrado. Curso de Pós-graduação em Psicologia Institucional, Universidade Federal do Espírito Santo, Espírito Santo, ES).

Ferreira, J. P. S. P. (2016). Memórias de uma viagem cartográfica: a gestão autônoma da medicação e o exercício do cuidado no capsi de vitória. (Dissertação de mestrado. Curso de Pós-graduação em Psicologia Institucional, Universidade Federal do Espírito Santo, Espírito Santo, ES).

Gaigher, G. L. (2018). A participação de crianças e familiares no cuidado em saúde mental: um grupo gam no capsi de Vitória-es. (Dissertação de mestrado. Curso de Pós-graduação em Psicologia Institucional, Universidade Federal do Espírito Santo, Espírito Santo, ES).

Guattari, F. (1981). Devir criança, malandro, bicha. In F. Guattari Revoluções Moleculares: pulsões políticas do desejo (pp. 64 - 69). Editora Brasilense: São Paulo.

Moraes, M. (2010). PesquisarCom: política ontológica e deficiência visual. In M. Moraes \& V Kastrup. Exercícios de ver e não ver: arte e pesquisa com pessoas com deficiência visual (pp. 26 - 51). Rio de Janeiro: Nau Editoria.

Passos, E., Kastrup, V. \& Escóssia, L. (Orgs). (2009). Pistas do método da cartografia: pesquisa-intervenção $e$ produção de subjetividade. Porto Alegre: Sulina.

Renault, L. (2015). A Análise em uma Pesquisa-Intervenção Participativa: $O$ Caso da Gestão Autônoma da Medicação. (Tese de doutorado. Curso de Pós-graduação em Psicologia, Universidade Federal Fluminense, Rio de Janeiro, RJ).

Selvatici, A.S. (2017). Uma abertura da máquina do mundo: cogestão $e$ conversa como exercícios de cultivo de margens por entre as rachaduras dos muros. (Dissertação de mestrado. Curso de Pós-graduação em Psicologia Institucional, Universidade Federal do Espírito Santo, Espírito Santo, ES).

Stern, D. (1992). O Mundo Interpessoal do Bebê.Uma Visão a partir da Psicanálise e da Psicologia do Desenvolvimento. Porto Alegre: Editora Artes Médicas Sul Ltda., RS.

Luciana Vieira Caliman é professora associada do Departamento de Psicologia e do Programa de Pós-graduação em Psicologia Institucional da Universidade Federal do Espírito Santo. É também doutora e mestre em Saúde Coletiva (UERJ).

E-mail: calimanluciana@gmail.com ORCID:https://orcid.org/0000-0001-8558$\underline{6562}$

Janaína Mariano César é professora adjunta do Departamento de Psicologia e do Programa de Pós-graduação em Psicologia Institucional da Universidade Federal do Espírito Santo. É também 
doutora em Educação (UFES) e Mestre em Psicologia (UFF/RJ).

E-mail: jhanainacesar@gmail.com

ORCID:https://orcid.org/0000-0001-6532-

$\underline{1380}$

Enviado em: 15/07/19 - Aceito em: 22/05/20 